\title{
Central Sleep Apnea
}

National Cancer Institute

\section{Source}

National Cancer Institute. Central Sleep Apnea. NCI Thesaurus. Code C116046.

The periodic cessation of breathing while asleep that occurs secondary to the decreased responsiveness of the respiratory center of the brain to carbon dioxide, resulting in alternating cycles of apnea and hyperpnea. 